\title{
Análise da Frequência em que Fontes Geradoras de Infiltração Ocorrem em Edifícios Inspecionados na Cidade de Aracaju-SE e Suas Manifestações Patológicas
}

\author{
Analysis of the Frequency in which Sources that Generate Infiltration Occur in Buildings \\ Inspected in the City of Aracaju-SE and their Pathological Manifestations
}

\section{Emanuella Carvalho ${ }^{1,2}$ orcid.org/0000-0002-3945-4152}

Monalisa Oliveira 1 (D) orcid.org/0000-0002-7278-8787

Eliana Monteiro 3,4 (ib) orcid.org/0000-0003-0842-779X

\footnotetext{
${ }^{1}$ Bacharelado em Engenharia Civil, Instituto Federal de Educação, Ciência e Tecnologia de Sergipe, Aracaju, Brasil,

2 Pós-graduação em Engenharia Diagnóstica, Instituto Brasileiro de Educação Continuada, Sergipe, Brasil,

${ }_{3}^{3}$ Departamento de Engenharia Civil, Escola Politécnica de Pernambuco, Universidade de Pernambuco, Recife, Brasil,

${ }^{4}$ Doutorado em Engenharia de Construção Civil, Universidade de São Paulo, São Paulo, Brasil.

E-mail do autor principal: Emanuella Carvalho emanuellaacarvalho@hotmail.com
}

\section{Resumo}

Por dois anos fiscalizando obras de manutenção predial, foi notável o grande transtorno causado por infiltrações nos sistemas construtivos. Chamou atenção a frequência com que as manifestações patológicas e os ambientes nos quais elas surgiam se repetiam. Com o objetivo de identificar quais as manifestações patológicas presentes geradas a partir do surgimento de infiltrações e avaliar a incidência das mesmas, foram inspecionados 15 edifícios residenciais distribuídos pela cidade de Aracaju-SE. A inspeção foi realizada de forma visual e contou com auxílio do teste de percussão com martelo de borracha, abrangendo tanto os ambientes de uso comum quanto o interior dos apartamentos. Durante o estudo notou-se que todos os edifícios apresentavam algum tipo de manifestação patológica, com foco no surgimento de manchas, fissuras, eflorescência e corrosão na armadura dos elementos estruturais. Juntamente a isso, foi verificado que surgem em sua maioria em lajes de ambientes abertos de uso comum, piscinas elevadas, jardineiras e fundo de laje com banheiro gerados por falta de manutenção e/ou falha na impermeabilização e revestimento. Tais informações podem auxiliar na elaboração de um manual de manutenção direcionado aos condomínios, reduzindo assim custos com reparações, aumentando a durabilidade e prolongando a vida útil das construções.

Palavras-Chave: Manutenção predial; Condomínios; Durabilidade; Vida útil.

\begin{abstract}
For two years supervising building maintenance works, the great inconvenience caused by infiltrations in the construction systems was notable. It drew attention to the frequency with which the pathological manifestations and the environments in which they arose were repeated. In order to identify the pathological manifestations present generated from the appearance of infiltrations and assess their incidence, 15 residential buildings in the city of Aracaju-SE were inspected. The inspection was carried out in a visual way and had the aid of a percussion test with a rubber hammer,
\end{abstract}




\title{
Análise da Frequência em que Fontes Geradoras de Infiltração Ocorrem em Edifícios Inspecionados na Cidade de Aracaju-SE e Suas Manifestações Patológicas
}

\begin{abstract}
covering both the common use environments and the interior of the apartments. During the study it was noted that all buildings had some type of pathological manifestation, with a focus on the appearance of stains, cracks, efflorescence and corrosion in the reinforcement of structural elements. Along with this, it was found that they appear mostly in open-plan slabs in common use, elevated swimming pools, planters and slab bottom with bathrooms generated by lack of maintenance and / or failure in waterproofing and covering. Such information can assist in the elaboration of a maintenance manual directed to condominiums, thus reducing repair costs, increasing durability and extending the useful life of buildings.
\end{abstract}

Key-words: Building maintenance; Condominiums; Durability; Useful life.

\section{Introdução}

Devido aos crescentes problemas de degradação precoce encontrados nas estruturas nas últimas duas décadas, incluir aspectos de projeto visando a durabilidade e o aumento da vida útil de estruturas de concreto armado vem se tornando foco na indústria da construção civil. [1]

As manifestações patológicas são desenvolvidas por meio de problemas recorrentes durante sua vida útil, estando relacionadas ao tempo de vida da construção, ao clima, aos materiais e técnicas construtivas utilizadas e ao nível de controle de qualidade realizado. [2]

É mais viável que seja implementado um planejamento de manutenções durante a elaboração do projeto construtivo, logo que há um crescimento progressivo nos custos de intervenções com o passar do tempo e à medida que manutenções e reparos se tornam cada vez mais onerosos. [1]

Conforme mostrado na Figura 1, a regra de Sitter apresenta essa evolução dos custos por meio de uma progressão geométrica de razão 5 .

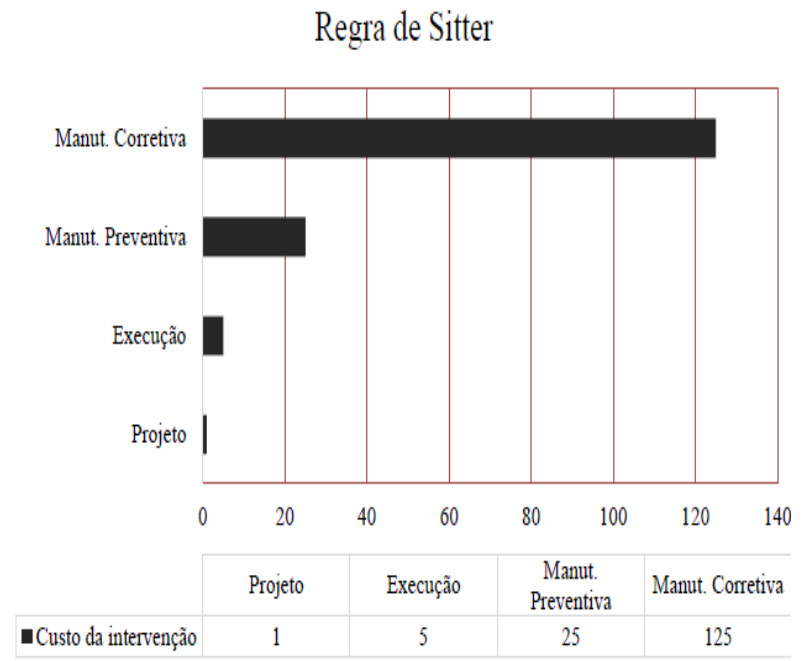

Figura 1: Evolução do custo de intervenção segundo Lei de Sitter.

FONTE: SITTER, 1984 apud RIBEIRO et al., 2014. [3]

Conhecendo-se as manifestações patológicas mais frequentes presentes nas edificações, é possível que as Construtoras e Condomínios se aliem para elaboração de um manual de manutenção que minimize a deterioração precoce das estruturas e com isso atenda a vida útil mínima exigida em norma e reduza os gastos com correções que poderiam ter sido evitadas já em projeto.

É de grande interesse dos síndicos que sejam realizadas manutenções preventivas visto que, de acordo com o Código Civil (Art. 1.348, V), "diligenciar a conservação e a guarda das partes comuns e zelar pela prestação dos serviços que interessem aos possuidores" são umas das competências do síndico. [4] Podendo o mesmo vir a responder por negligências caso ocorram acidentes por falta de manutenção.

Diante da importância do tema e durante experiências profissionais ter sido observado que em grande parte de edificações visitadas haviam infiltrações que causavam grandes danos e transtornos aos condôminos do local, o presente trabalho apresenta um estudo de caso realizado em 15 condomínios na cidade de Aracaju-SE, no qual, por meio de inspeção foi capaz de identificar as manifestações patológicas mais frequentes, pontuando os sistemas construtivos mais comuns em que elas surgiam, além de analisar possíveis nexos causais e suas consequências.

\section{Infiltrações em Edifícios}

As infiltrações são problemas comumente encontrados nas edificações. Têm-se as seguintes origens as umidades nas construções:

- $\quad$ Oriundas durante a construção - Devido à presença de água em quase todas as etapas de execução de uma obra, pode 
haver infiltrações que desaparecerão nos primeiros meses de construção. Como por exemplo nos poros do concreto e argamassas, na tinta.

- $\quad$ Oriundas por capilaridade - Quando ocorre a ascensão da água presente no solo úmido. Encontrada geralmente em baldrames, sofrendo influência do nível do lençol freático.

- $\quad$ Oriundas por chuva - São ocasionadas devido diversos fatores que são diretamente influenciados pela direção, velocidade do vento, intensidade da precipitação e fatores da própria construção (impermeabilização, porosidade, presença de fissuras, etc).

- $\quad$ Resultantes de vazamentos em redes hidráulicas - Gerados por danos em tubulações embutidas nos revestimentos e/ou alvenarias.

- $\quad$ Condensação - Devido a água presente no ambiente ao se instalar na estrutura. [5]

Com a presença contínua de infiltrações em uma estrutura, podem surgir manifestações patológicas que afetam seu desempenho. As manifestações patológicas "são decorrentes do surgimento de anomalias nas edificações, que podem ser provenientes desde problemas na fundação, estrutura e acabamento, até nos próprios materiais utilizados". [6]

Com o surgimento de infiltrações nas edificações, se não tratadas de imediato ou em um curto período de tempo após sua identificação, ocasionará manifestações patológicas em diversos sistemas. Esse problema pode aparecer de diversas formas, mas as principais manifestações patológicas vêm através de manchas nas paredes e forro, destacamento de revestimento cerâmico, eflorescências, corrosão da armadura, caso ocorra dentro da estrutura, podendo levar até o colapso. [7]

\section{Manifestações Patológicas Devido Infiltrações}

As principais manifestações patológicas são conceituadas a seguir:

- Manchas de água e eflorescência:
As manchas são geradas com a presença contínua e excessiva de água que mudam a tonalidade do elemento, afetando 0 seu desempenho estético.

Já a eflorescência ocorre quando a água ácida ou a água com concentração alta de cloretos e sulfatos, ao adentrar-se nos poros capilares do concreto, dissolve o hidróxido de cálcio da pasta de cimento que pode, posteriormente, reagir com o dióxido de carbono do ar formando o carbonato de cálcio $\left(\mathrm{CaCO}_{3}\right)$. Este sal ao ser carregado pela água, deposita-se na superfície da camada de revestimento, formando uma mancha branca. [8] Como consequência, "as eflorescências podem alterar a aparência da superfície sobre a qual se depositam e em determinados casos seus sais constituintes podem ser agressivos, causando desagregação profunda". [9]

- $\quad$ Estalactites:

"A ação da percolação da água pelo concreto, já fissurado ou muito permeável, dilui os compostos da pasta de cimento através da lixiviação, formando manchas brancas que podem até mesmo aumentar de volume formando estalactites". [10]

- Destacamento ou descolamento do revestimento:

O descolamento do revestimento ocorre quando há perda da aderência entre as camadas do revestimento ou entre a base e o substrato. Sendo gerado quando surge tensão superior a capacidade da ligação. [11]

Pode ser identificado quando no teste de percussão apresenta um som "cavo" ou quando há o estufamento do revestimento, podendo levar ao total destacamento.

- Fissuras:

As fissuras podem surgir em uma edificação por diversas razões, dentre os principais por variação de temperatura, recalque do solo, deformações nos elementos estruturais, sobrecargas e por reações químicas, como ocorre no processo de corrosão.

A norma 6118 da Associação Brasileira de Normas Técnicas [12] define as exigências mínimas em função da classe de agressividade ambiental para que se mantenha a durabilidade da estrutura quanto a abertura de fissuras. 
As fissuras podem ser classificadas como ativas ou passivas, ou seja, se sofrem ou não movimentações ao longo do tempo. Independente da classificação, é imperioso que seja escolhido o tratamento adequado para o caso, logo que é através das fissuras que a armadura, que antes estava protegida pelo concreto, agora se encontra dando espaço para a penetração dos agentes agressores que despassivam a armadura e a deixam vulneráveis a corrosão. [13]

\section{- $\quad$ Corrosão nas armaduras:}

Com o pH do concreto alcalino, em torno de 12, surge um filme que funcionará como uma película protetora de óxido de ferro $\left(\mathrm{Fe}_{3} \mathrm{O}_{4}\right)$ que cobrirá a superfície da armadura de aço, chamado por alguns autores de filme óxido. Esse filme tem a função de diminuir significativamente a taxa de dissolução da armadura, protegendo-a contra a corrosão na ausência de agentes externos agressivos. [3]

A corrosão só ocorrerá com a presença de 3 (três) fatores: um eletrólito, como a água presente nos poros do concreto, oxigênio presente no ambiente e diferença de potencial, podendo ser gerada por diferença de umidade, mudança de $\mathrm{pH}$, aeração e tensões no concreto ou no aço ou demais causas que causem o rompimento do filme óxido que protege a armadura. [14]

Há dois processos de corrosão, a direta e a eletroquímica, esta última é de grande importância no campo da corrosão de armaduras. É explicado pelo autor, em suma, que o processo de corrosão eletroquímica se dá pela dissolução dos átomos do metal no meio aquoso como íons, havendo o princípio de ionização do metal que passa à solução na forma de cátions e a formar elétrons livres que ficam na superfície do metal, perdendo energia até estabelecer um equilíbrio com o meio. Mas, se os elétrons livres continuarem a ser removidos, 0 metal continuará a se dissolver até estabelecer equilíbrio novamente. [15]

A corrosão pode ser classificada de acordo com diversas características, como segundo a sua morfologia, causas ou mecanismos, fatores mecânicos, meio corrosivo e a localização do ataque, sendo essa a mais adequada para entender o processo corrosivo no ambiente construtivo, podendo ocorrer de forma uniforme, por pite, intergranular, transgranular, dentre outras. Sendo as duas primeiras com maiores índices de incidência de manifestações patológicas no concreto armado. [16]

\section{Materiais e Métodos}

Foram visitados 15 (quinze) condomínios localizados em bairros distintos da cidade de Aracaju-SE que estavam em fase inicial da execução de manutenções corretivas, nos quais foram realizadas inspeções visuais e executado teste de percussão com martelo de borracha para identificar possível som cavo nos sistemas construtivos dos ambientes visitados. Pôde-se constatar durante as inspeções quais eram as manifestações patológicas visíveis e iminentes causadas por infiltrações nos edifícios. De posse dos registros dos dados, foi realizada análise quantitativa dos mesmos para verificar o percentual dessas manifestações patológicas assim como dos locais em que surgiram as infiltrações.

Na Tabela 1 é apresentada uma breve descrição das manifestações patológicas encontradas nos edifícios dos Condomínios vistoriados e os locais em que as mesmas surgiram. Foi adotada nomenclatura genérica para cada Condomínio.

Tabela 1: Descrição das manifestações patológicas identificadas nos edifícios e seus determinados locais de surgimento.

\begin{tabular}{|c|c|c|c|}
\hline Cond. & $\begin{array}{c}\text { Idade } \\
\text { Aproximada } \\
\text { (anos) }\end{array}$ & $\begin{array}{c}\text { Manifestação } \\
\text { Patológica }\end{array}$ & $\begin{array}{c}\text { Local de } \\
\text { Surgimento }\end{array}$ \\
\hline $\mathbf{A}$ & 20 & $\begin{array}{c}\text { Destacamento } \\
\text { de revestimento }\end{array}$ & $\begin{array}{l}\text { Varanda aberta } \\
\text { (sem esquadria) }\end{array}$ \\
\hline \multirow{3}{*}{ B } & \multirow{3}{*}{25} & $\begin{array}{c}\text { Corrosão na } \\
\text { armadura }\end{array}$ & \multirow[t]{2}{*}{$\begin{array}{l}\text { Reservatório } \\
\text { elevado }\end{array}$} \\
\hline & & Eflorescência & \\
\hline & & $\begin{array}{l}\text { Corrosão na } \\
\text { armadura }\end{array}$ & $\begin{array}{c}\text { Fundo da laje de } \\
\text { banheiro }\end{array}$ \\
\hline C & 30 & $\begin{array}{c}\text { Eflorescência, } \\
\text { Estalactites, } \\
\text { Corrosão na } \\
\text { armadura }\end{array}$ & $\begin{array}{c}\text { Fundo da laje de } \\
\text { banheiro }\end{array}$ \\
\hline D & 35 & $\begin{array}{c}\text { Destacamento } \\
\text { de revestimento, } \\
\text { Fissuras, } \\
\text { Manchas de } \\
\text { umidade }\end{array}$ & $\begin{array}{c}\text { Junta de } \\
\text { dilatação } \\
\text { estrutural (entre } \\
\text { vigas) }\end{array}$ \\
\hline $\mathbf{E}$ & 15 & $\begin{array}{c}\text { Destacamento } \\
\text { de revestimento, } \\
\text { Fissuras, } \\
\text { Manchas de } \\
\text { umidade (com } \\
\text { limo) }\end{array}$ & $\begin{array}{c}\text { Fundo da laje de } \\
\text { Playground com } \\
\text { piso } \\
\text { poroso/fissurado }\end{array}$ \\
\hline & & $\begin{array}{c}\text { Fissuras, } \\
\text { Corrosão na }\end{array}$ & $\begin{array}{c}\text { Fundo de piscina } \\
\text { elevada }\end{array}$ \\
\hline $\mathbf{F}$ & 7 & $\begin{array}{c}\text { armadura, } \\
\text { Eflorescência, } \\
\text { Manchas de } \\
\text { umidade }\end{array}$ & $\begin{array}{c}\text { Fundo da laje de } \\
\text { Playground com } \\
\text { piso } \\
\text { poroso/fissurado }\end{array}$ \\
\hline
\end{tabular}




\begin{tabular}{|c|c|c|c|}
\hline $\mathbf{G}$ & 10 & $\begin{array}{l}\text { Destacamento } \\
\text { de revestimento, } \\
\text { Fissuras, } \\
\text { Manchas de } \\
\text { umidade }\end{array}$ & $\begin{array}{l}\text { Fundo da laje de } \\
\text { cobertura }\end{array}$ \\
\hline \multirow[b]{2}{*}{ H } & \multirow[b]{2}{*}{15} & \multirow{2}{*}{$\begin{array}{l}\text { Fissuras, } \\
\text { Eflorescência, } \\
\text { Manchas de } \\
\text { umidade }\end{array}$} & $\begin{array}{c}\text { Fundo de piscina } \\
\text { elevada }\end{array}$ \\
\hline & & & $\begin{array}{c}\text { Fundo da laje de } \\
\text { Playground com } \\
\text { piso } \\
\text { poroso/fissurado }\end{array}$ \\
\hline \multirow[b]{2}{*}{$\mathbf{I}$} & \multirow[b]{2}{*}{18} & \multirow[b]{2}{*}{$\begin{array}{l}\text { Fissuras, } \\
\text { Eflorescência, } \\
\text { Manchas de } \\
\text { umidade }\end{array}$} & $\begin{array}{c}\text { Fundo de piscina } \\
\text { elevada }\end{array}$ \\
\hline & & & $\begin{array}{c}\text { Fundo da laje de } \\
\text { Playground com } \\
\text { piso } \\
\text { poroso/fissurado }\end{array}$ \\
\hline J & 8 & $\begin{array}{l}\text { Fissuras de } \\
\text { retração, } \\
\text { Eflorescência, } \\
\text { Estalactites, } \\
\text { Manchas de } \\
\text { umidade }\end{array}$ & $\begin{array}{l}\text { Piso e fundo da } \\
\text { laje de cobertura }\end{array}$ \\
\hline $\mathbf{K}$ & 15 & $\begin{array}{l}\text { Destacamento } \\
\text { de revestimento, } \\
\text { Corrosão na } \\
\text { armadura, } \\
\text { Manchas de } \\
\text { umidade }\end{array}$ & $\begin{array}{l}\text { Fundo de } \\
\text { jardineira }\end{array}$ \\
\hline \multirow[b]{2}{*}{$\mathbf{L}$} & \multirow[b]{2}{*}{18} & \multirow{2}{*}{$\begin{array}{l}\text { Fissuras, } \\
\text { Eflorescência, } \\
\text { Manchas de } \\
\text { umidade }\end{array}$} & $\begin{array}{c}\text { Fundo de piscina } \\
\text { elevada }\end{array}$ \\
\hline & & & $\begin{array}{c}\text { Fundo da laje de } \\
\text { Playground com } \\
\text { piso } \\
\text { poroso/fissurado }\end{array}$ \\
\hline \multirow{7}{*}{ M } & \multirow{7}{*}{40} & \multirow{7}{*}{$\begin{array}{c}\text { Fissuras, } \\
\text { Eflorescência, } \\
\text { Manchas de } \\
\text { umidade, } \\
\text { Corrosão na } \\
\text { armadura, } \\
\text { Estalactites, } \\
\text { Destacamento } \\
\text { de revestimento }\end{array}$} & $\begin{array}{c}\text { Fundo de piscina } \\
\text { elevada }\end{array}$ \\
\hline & & & $\begin{array}{c}\text { Fundo da laje de } \\
\text { Playground com } \\
\text { piso } \\
\text { poroso/fissurado }\end{array}$ \\
\hline & & & $\begin{array}{c}\text { Junta de } \\
\text { dilatação } \\
\text { estrutural (entre } \\
\text { vigas) }\end{array}$ \\
\hline & & & $\begin{array}{l}\text { Fundo de } \\
\text { jardineira }\end{array}$ \\
\hline & & & $\begin{array}{c}\text { Parede das } \\
\text { Fachadas } \\
\text { (internas e } \\
\text { externas) } \\
\end{array}$ \\
\hline & & & $\begin{array}{c}\text { Reservatório } \\
\text { elevado }\end{array}$ \\
\hline & & & $\begin{array}{c}\text { Fundo da laje de } \\
\text { banheiro }\end{array}$ \\
\hline \multirow{5}{*}{$\mathbf{N}$} & \multirow{5}{*}{35} & \multirow{5}{*}{$\begin{array}{c}\text { Fissuras, } \\
\text { Eflorescência, } \\
\text { Manchas de } \\
\text { umidade, } \\
\text { Corrosão na } \\
\text { armadura, } \\
\text { Estalactites, } \\
\text { Destacamento } \\
\text { de revestimento }\end{array}$} & $\begin{array}{c}\text { Fundo de piscina } \\
\text { elevada }\end{array}$ \\
\hline & & & $\begin{array}{c}\text { Fundo da laje de } \\
\text { Playground com } \\
\text { piso } \\
\text { poroso/fissurado }\end{array}$ \\
\hline & & & $\begin{array}{c}\text { Junta de } \\
\text { dilatação } \\
\text { estrutural (entre } \\
\text { vigas) }\end{array}$ \\
\hline & & & $\begin{array}{l}\text { Fundo de } \\
\text { jardineira }\end{array}$ \\
\hline & & & $\begin{array}{l}\text { Parede das } \\
\text { Fachadas }\end{array}$ \\
\hline
\end{tabular}

\begin{tabular}{|c|c|c|c|}
\hline & & & $\begin{array}{l}\text { (internas e } \\
\text { externas) }\end{array}$ \\
\hline \multirow{3}{*}{0} & \multirow{3}{*}{26} & \multirow{3}{*}{$\begin{array}{c}\text { Fissuras, } \\
\text { Eflorescência, } \\
\text { Manchas de } \\
\text { umidade, } \\
\text { Corrosão na } \\
\text { armadura, } \\
\text { Destacamento } \\
\text { de revestimento }\end{array}$} & $\begin{array}{c}\text { Parede das } \\
\text { Fachadas } \\
\text { (internas e } \\
\text { externas) } \\
\end{array}$ \\
\hline & & & $\begin{array}{l}\text { Cômodos abertos } \\
\text { (sem esquadria) }\end{array}$ \\
\hline & & & $\begin{array}{l}\text { Fundo de } \\
\text { jardineira }\end{array}$ \\
\hline
\end{tabular}

Fonte: AUTORES (2019).

Nas Figuras 2 e 3 são exemplificadas as manifestações patológicas comumente identificadas nos Condomínios estudados.

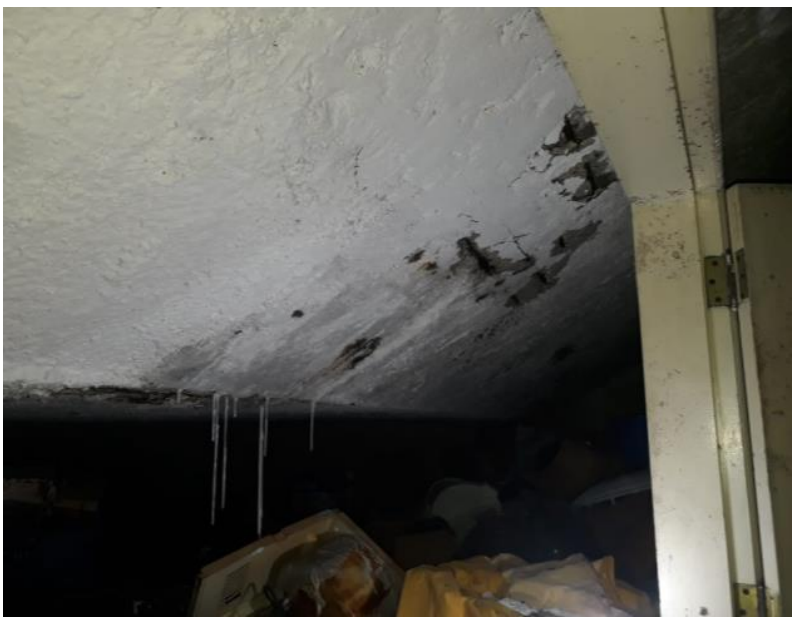

Figura 2: Corrosão de armadura com descolamento de cobrimento do concreto, fissuras, eflorescência e estalactites identificados em piscina no Condomínio N. FONTE: AUTORES (2019).

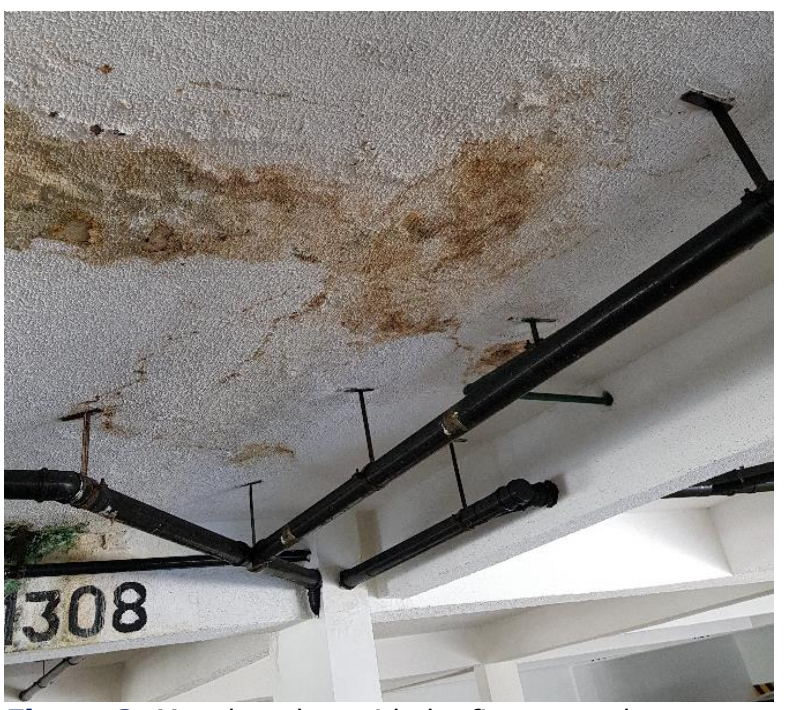

Figura 3: Manchas de umidade, fissuras e destacamento do revestimento, identificados em laje no Condomínio E. FONTE: AUTORES (2019). 


\section{Resultados}

Tendo conhecido os Condomínios e realizada a inspeção, na Tabela 2 são apresentados os dados encontrados, as regiões construtivas das edificações nas quais havia incidência de infiltrações.

Tabela 2: Locais nos quais surgiram infiltrações nos Condomínios.

\begin{tabular}{c|c|c}
\hline Local de Surgimento & Condomínio & Total \\
\hline Fundo de jardineira & K, M, N, O & 4 \\
\hline $\begin{array}{c}\text { Junta de dilatação } \\
\text { estrutural (entre vigas) }\end{array}$ & D, M, N & 3 \\
\hline Fundo de piscina elevada & C, F, H, I, L, M, N & 7 \\
\hline $\begin{array}{c}\text { Fundo da laje de } \\
\text { Playground com piso } \\
\text { poroso/fissurado }\end{array}$ & E, F, H, I, L, M, N & 7 \\
\hline $\begin{array}{c}\text { Parede das Fachadas } \\
\text { internas e externas) }\end{array}$ & M, N, O & 3 \\
\hline $\begin{array}{c}\text { Cômodo/varanda aberto } \\
\text { (sem esquadria) }\end{array}$ & A, O & 2 \\
\hline Laje de cobertura & G, J & 2 \\
\hline Fundo da laje de banheiro & C, B, D, M & 4 \\
\hline $\begin{array}{c}\text { Reservatório elevado } \\
\text { Fonte: AUTORES (2019) }\end{array}$ & B, M & 2
\end{tabular}

Fonte: AUTORES (2019).

Além das zonas em que foi identificada a presença de infiltração, registrou-se também a incidência das anomalias encontradas nesses locais, apresentado na Tabela 3.

Tabela 3: Manifestações patológicas identificadas nos Condomínios.

\begin{tabular}{c|c|c}
\hline $\begin{array}{c}\text { Manifestação } \\
\text { Patológica }\end{array}$ & Condomínio & Total \\
\hline $\begin{array}{c}\text { Destacamento de } \\
\text { revestimento }\end{array}$ & A, D, E, G, K, M, N, O & 8 \\
\hline Eflorescência & B, C, F, H, I, J, L, M, N, & 10 \\
\hline Corrosão na armadura & B, C, D, F, H, K, L, M, \\
N, O
\end{tabular}

Fonte: AUTORES (2019).

\section{Discussão}

Analisando os dados obtidos e apresentados anteriormente nas Tabelas 2 e 3, observou-se que se gerados gráficos com os resultados, obtendo-se então uma representação percentual da incidência de locais com presença de infiltração e as consequentes manifestações patológicas geradas, poderiam ser verificados de forma mais clara e ampla. Com esse intuito, dividindo da mesma forma apresentada nas tabelas de resultados, a Figura 4 apresenta a porcentagem da frequência de infiltrações identificadas em cada um dos locais nos condomínios estudados.

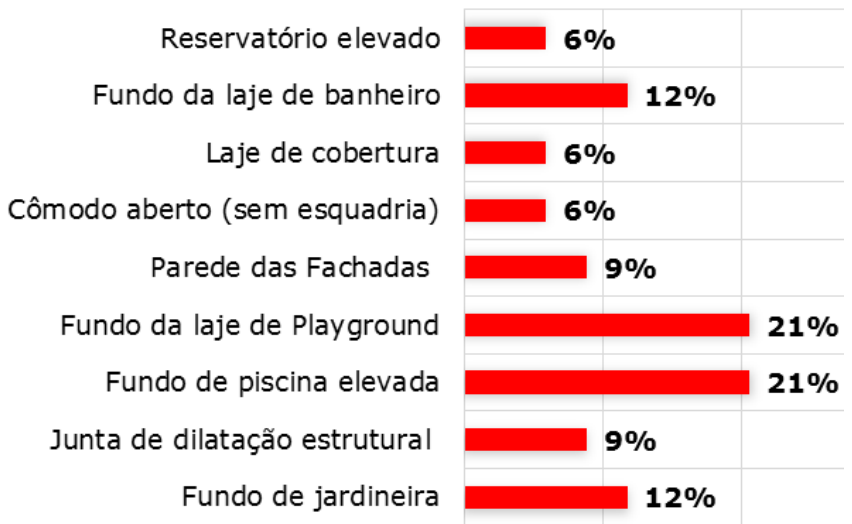

Figura 4: Percentual dos locais nos quais surgiram infiltrações nos edifícios.

FONTE: AUTORES (2019).

Portanto, através da Figura 4 é possível afirmar que as regiões nas quais os condomínios estudados devem dedicar imediata atenção são as piscinas elevadas e áreas de ambientes comuns sem cobertura, geralmente de Pavimentos superiores como Playground, logo que foram identificados em $21 \%$ dos casos. Nos Condomínios inspecionados, se conhecido o tempo de vida útil dos sistemas de revestimento, rejuntamento, impermeabilização e efetuadas as manutenções preventivas no tempo certo, evitaria o surgimento de danos à edificação e maior custo com as correções, sendo de suma importância que durante a elaboração de um manual de manutenção seja especificado o tempo de vida útil de cada sistema construtivo. Logo que se observou o alto nível de porosidade dos pisos cerâmicos, assim como da falta de manutenção do sistema de rejuntamento, facilitando percolação de água no interior dos elementos estruturais.

O mesmo ocorreu com as jardineiras e lajes abaixo de banheiros, com constante presença de água e falta de manutenção da impermeabilização e rejunte, respectivamente.

Na Figura 5 são apresentadas as porcentagens da frequência de cada manifestação patológica constatada nos edifícios vistos. 


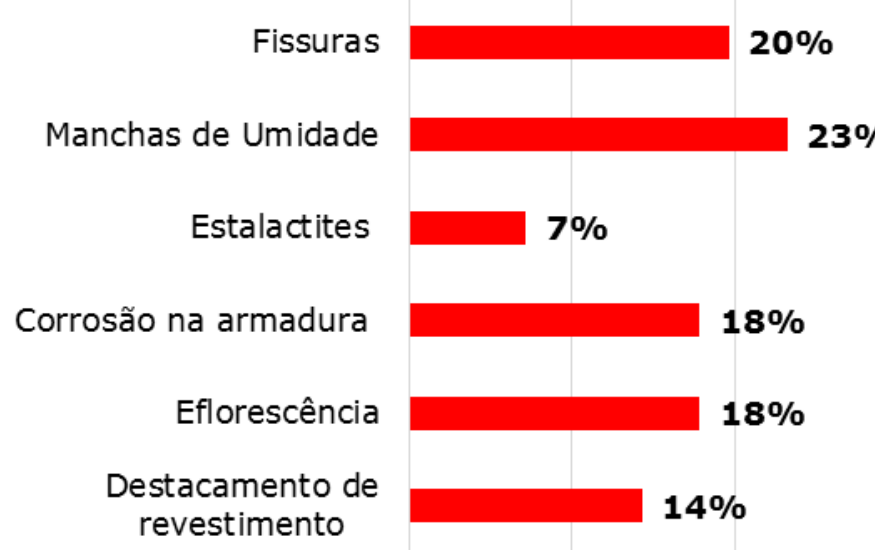

Figura 5: Percentual das manifestações patológicas identificadas nos edifícios. FONTE: AUTORES (2019).

Dentre as sete manifestações patológicas encontradas, percebe-se que as mais comuns foram manchas de umidade, fissuras, eflorescência e corrosão na armadura da estrutura, esses dois últimos com o mesmo percentual.

Com esses resultados destaca-se a constante presença de água nos diversos ambientes das edificações, que somada a falha e/ou falta de manutenção dos sistemas de impermeabilização e revestimento resulta no surgimento de manchas, que é um dos primeiros indicadores de infiltração.

Com o uso do martelo de borracha durante teste de percussão em determinados elementos estruturais que apresentavam fissuras no concreto, pôde-se constatar o destacamento iminente e a presença de corrosão na armadura antes oculta. Ressaltando a baixa espessura dos cobrimentos de concreto que juntamente com a alta classe de agressividade do ambiente, com grande concentração de íons cloreto na atmosfera, facilita o processo de eflorescência e sobretudo de corrosão na armadura.

Como consequência dessas manifestações patológicas causadas por infiltrações, se negligenciadas trazem riscos à saúde dos presentes, pela proliferação de fungos no local, e em casos mais graves pode levar ao colapso da estrutura, principalmente se tratando de corrosão localizada (por pite) na armadura.

Portanto, é notável que determinados locais na edificação apresentam maior probabilidade de surgir infiltrações. E as manifestações patológicas geradas por consequência dessas infiltrações possuem o mesmo padrão. Se faz necessário que seja realizada uma análise mais criteriosa para verificar a causa da vulnerabilidade encontrada nos edifícios, seja ela por problemas construtivos, de manutenção ou um conjunto de falhas, para que haja precaução quanto a construção de novos edifícios. E mesmo a manutenção não sendo a causa principal, é de suma importância sua realização periódica para que se reforme a vida útil da estrutura e nos demais sistemas construtivos que compõem uma edificação, evitando futuros transtornos, riscos e gastos.

\section{Conclusões}

As infiltrações são grandes vilãs das edificações quando se trata de vida útil das construções. De posse dos dados obtidos, com o presente estudo de caso observou-se que nos edifícios estudados foi identificada uma frequência de $23 \%$ do surgimento de manchas causadas por infiltrações, $20 \%$ de fissuras e $18 \%$ de eflorescência e corrosão na armadura dos elementos estruturais. Tais manifestações patológicas eram comumente vistas fundo de lajes que possuíam pisos visivelmente porosos em ambientes sem cobertura nos pavimentos superiores, em piscinas elevadas, fundo de laje com banheiro e jardineiras, que acumulam água e raramente são feitas manutenções na impermeabilização e no sistema de rejuntamento.

Portanto, foi possível verificar quais os locais em que se deve dedicar mais atenção e quais foram as manifestações patológicas mais recorrentes identificadas visualmente. Podendo auxiliar de forma efetiva na elaboração de um manual de manutenção preventiva periódica dos sistemas construtivos para condomínios quanto a infiltrações.

\section{Agradecimentos}

Agradeço a professora Dra. Eliana Monteiro, pelo suporte e dedicação em suas orientações prestadas que enriqueceram este trabalho. A Engenheira Civil Ana Cecília pelo auxílio e material fornecido imprescindíveis e a todos que fizeram da realização deste trabalho possível.

\section{Referências}

[1] MEDEIROS et al; Durabilidade e vida útil das estruturas de concreto. IBRACON, 2011.

[2] SANTOS, C. R. B. et al. Incidência de Manifestações Patológicas em Edificações Residenciais na Região Metropolitana do Recife (RMR). REPA, Vol. 2, No. 3., 2017. 


\section{Análise da Frequência em que Fontes Geradoras de Infiltração Ocorrem em Edifícios}

Inspecionados na Cidade de Aracaju-SE e Suas Manifestações Patológicas

[3] RIBEIRO, D. V. et al. Corrosão em Estruturas de concreto armado: teoria, controle e métodos de análise. Rio de Janeiro: Elsevier, 2014.

[4] BRASIL. Lei n. 10.406, 10 de janeiro de 2002. Institui o Código Civil - Art. 1.348, V. Diário Oficial da União, Brasília, DF, 11 jan. 2002. Disponível em:

<http://www.planalto.gov.br/ccivil_03/leis/2002/ L10406compilada.htm>. Acesso em: 06 de abril de 2019.

[5] SOUZA, M. F. Patologias Ocasionadas Pela Umidade Nas Edificações. Departamento de Engenharia de Materiais de Construção. UFMG. 2008.

[6] PRESOTTO, M. I. M., EBERLE, C. R., TONI, R. D. PERÍCIAS DE ENGENHARIA NA CONSTRUÇÃO CIVIL - ESTUDO DE CASO. Revista Técnico*Científica do Crea-PR - ISSN 2358-5420 -Edição especial- Setembro de 2017.

[7] RODRIGUES, R. M. et al. ERROS, DIAGNÓSTICOS E SOLUÇÕES DE IMPERMEABILIZAÇÃO NA CONSTRUÇÃO CIVIL. INTERSCENTIA, Vol. 4, No 2, Ano 2016.

[8] MACEDO, J. V. et al. MANIFESTAÇÕES PATOLÓGICAS CAUSADAS PELA UMIDADE DEVIDO À FALHA OU AUSÊNCIA DE IMPERMEABILIZAÇÃO: ESTUDO DE CASO. CONPAR2017 - Recife, 30 e 31 de agosto de 2017.

[9] SILVA, I. T. S. IDENTIFICAÇÃO DOS FATORES QUE PROVOCAM EFLORESCÊNCIA NAS CONSTRUÇÕES EM ANGICOS/RN. Monografia apresentada a UNIVERSIDADE FEDERAL RURAL DO SEMI-ÁRIDO. Angicos-RN, 2011.

[10] BASTOS, L. O,, RAMPINELLI, F. G., TOSTA, J. P. VÍCIOS CONSTRUTIVOS: DESCONFORMIDADES ÀS NORMAS E SUA FREQUÊNCIA. XIX COBREAP - CONGRESSO BRASILEIRO DE ENGENHARIA DE AVALIAÇÕES E PERÍCIAS - IBAPE/PR - 2017.

[11] RHOD, A. B. Manifestações Patológicas em Revestimentos Cerâmicos: Análise da Frequência de Ocorrência em Áreas Internas de Edifícios em Uso em Porto Alegre. Monografia apresentada a Universidade Federal do Rio Grande do Sul. Julho, 2011.

[12] ASSOCIAÇÃO BRASILEIRA DE NORMAS TÉCNICAS. NBR 6118. Projeto de estruturas de concreto - Procedimento. Rio de Janeiro: ABNT, 2014.
[13] LANÇA, T. TRINCAS NAS EDIFICAÇÕES: UMA REVISÃO PRÁTICA BASEADA NO PROCESSO DE CAUSA X EFEITO. Monografia apresentada ao Departamento de Engenharia de Materiais e Construção da Universidade Federal de Minas Gerais. Março/2014.

[14] CUNHA, A. C. Q., HELENE, P. R. L. Despassivação das Armaduras de Concreto por Ação da Carbonatação. São Paulo, 2001. 100p. Dissertação (Mestrado) - Escola Politécnica da Universidade de São Paulo.

[15] HELENE, P. R. D. L. Contribuição ao Estudo da Corrosão em Armaduras de Concreto Armado. Tese apresentada à Escola Poli-técnica da Universidade de São Paulo. São Paulo, 1993.

[16] GENTIL, V. Corrosão. Rio de Janeiro: LTC, 1996. 